\title{
Acertijos y adivinanzas en el periódico sefardí Ilustra Güerta de Historia (Viena, 1880-1882)
}

\author{
María Sánchez Pérez \\ Universidad de Salamanca
}

El periódico sefardí Ilustra Güerta de Historia fue publicado en Viena entre 1880 y 1882. Estaba dirigido por Šem Tob Semo, una de las personalidades más importantes de la comunidad sefardí de Viena. Este periódico publicaba, fundamentalmente, novelas por entregas, pero también diferentes muestras de la cultura popular en la sección titulada «Sala de pasatiempo». En esta sección apareció un buen número de adivinanzas y acertijos en judeoespañol, casi todos ellos desconocidos en los estudios sefardíes. El objetivo de este artículo es dar a conocer esos acertijos, mostrar sus paralelos con la tradición hispánica e intentar rastrear sus posibles fuentes.

Palabras Clave: Ilustra Güerta de Historia; Šem Tob Semo; judeoespañol; sefardíes; prensa; oralidad; acertijo; adivinanza; cultura popular.

Riddles and Puzzles in the Sephardi Newspaper Ilustra Güerta de Historia (VienNA, 1880-1882). - The Sephardic newspaper Ilustra Güerta de Historia was published in Vienna between 1880 and 1882. It was run by Šem Tob Semo, one of the most influential figures of the Sephardic community of Vienna. This newspaper specialized in serial novels, yet it also published pieces of popular culture, in a section entitled "Sala de pasatiempo". This section included many riddles in Judeo-Spanish, almost completely unknown in Sephardic studies. The aim of this article is to present these Judeo-Spanish riddles, tracing their parallelisms with the Spanish tradition and attempting to establish their possible sources.

KeYwords: Ilustra Güerta de Historia; Šem Tob Semo; Judeo-Spanish; Sephardic Press; Orality; Riddle; Popular Culture.

Las investigaciones en torno a la prensa sefardí que vienen sucediéndose desde las últimas décadas del siglo XX demuestran la importancia que tiene el estudio de estas publicaciones periódicas para conocer los

\footnotetext{
*mariasanchezperez@usal.es
} 
modos de vida y el entorno cultural de las comunidades sefardíes desde mediados del siglo XIX hasta la Segunda Guerra Mundial ${ }^{1}$.

Como sabemos, la difusión de la prensa periódica fue un factor decisivo en el desarrollo de las comunidades sefardíes debido a que gracias a la adopción de este género -que ya estaba arraigado en las literaturas occidentales- entraron nuevos aires e influjos en el tradicional mundo sefardi ${ }^{2}$. Recordemos además que «la introducción de la imprenta en el Imperio otomano se debió a los sefardíes, quienes la tuvieron como monopolio hasta 1727» y por ello crearon una activa industria editorial en diferentes ciudades como Salónica, Esmirna, Constantinopla, Viena, etc. ${ }^{3}$. Precisamente nuestra atención se va a centrar en este trabajo en una publicación vienesa: Ilustra Güerta de Historia ${ }^{4}$.

\section{La COMUNIDAD SEFARDí DE VIENA Y El PERIÓdICO ILUSTRA GÜERTA DE HISTORIA}

Desde principios del siglo XVIII existía en la ciudad de Viena una comunidad sefardí que había sido fundada por judíos provenientes de Constantinopla y otros lugares del Imperio otomano ${ }^{5}$. Adolf von Zemlinsky sitúa concretamente la fundación en $1738^{6}$. A mediados de la centuria se

${ }^{1}$ Este trabajo se inscribe dentro del proyecto de investigación «Los sefardíes ante sí mismos y sus relaciones con España. III» (FFI2012-31625) del Ministerio de Economía y Competitividad.

${ }^{2}$ E. Romero, La creación literaria en lengua sefardí (Madrid: MAPFRE, 1992), 179.

${ }^{3}$ P. Díaz-Mas, Los sefardíes. Historia, lengua y cultura (Barcelona: Riopiedras, 2006), 74.

${ }^{4}$ M. D. Gaon, A Bibliography of the Judeo-Spanish (Ladino) Press (heb.) (Jerusalem: Ben Zvi Institute y The Hebrew University, 1965), núm. 13.

${ }^{5}$ Para algunos hechos históricos que afectaron a la comunidad de Viena y que se reflejan en coplas sefardíes, véase E. Romero, Entre dos (o más) fuegos. Fuentes poéticas para la historia de los sefardies de los Balcanes (Madrid: CSIC, 2008), especialmente referencias en pág. 922 (s.v. Viena).

${ }^{6}$ Apud M. Studemund-Halévy, «Shem Tov Semo, Sefardi Vienna and the Cradle of Judezmo Philology», en P. Díaz-Mas y M. Sánchez Pérez (eds.), Los sefardíes ante los retos del mundo contemporáneo. Identidad y mentalidades (Madrid: CSIC, 2010), 317-331: 318. El texto está tomado de la obra de Adolf von Zemlinsky -al que volveremos a referirnos más adelante-, quien en 1888 escribió una Historya de 
convirtió en uno de los centros editoriales más importantes y cabe destacar que la comunidad sefardí de Viena «llegó a alcanzar gran peso en el sefardismo oriental, pese a que los judíos de origen español eran minoría entre una judería fundamentalmente asquenazí» ${ }^{7}$. A partir de mediados del siglo XIX Viena se convirtió no solo en un referente industrial y financiero, sino también en un centro artístico y cultural de primer orden. Debido a ese crecimiento de la ciudad como centro comercial e intelectual, numerosos sefardíes de la zona de Turquía y los Balcanes se trasladaron y se asentaron allí. Otros acudían debido a sus negocios, ya que Viena se convirtió en un enclave sefardí en el centro de Europa y fue fundamental en las relaciones económicas entre los sefardíes de Occidente y Oriente. También se dieron numerosos casos de familias acomodadas sefardíes de los Balcanes que enviaban a sus hijos a estudiar en la Universidad de Viena, con lo cual la ciudad se convirtió en un importante centro cultural para intelectuales sefardíes. Algunos de aquellos estudiantes fundaron en 1896 la sociedad Esperanza, que fue una institución clave en la vida intelectual sefardí de Viena, ya que se convirtió en un pilar de la identidad sefardí en un momento de profundas transformaciones en las comunidades sefardíes ${ }^{8}$. Todos estos aspectos influyeron decisivamente en la evolución de la propia comunidad sefardí de la ciudad, así como el hecho del importante desarrollo de la imprenta judía. Sin embargo, la Primera Guerra Mundial truncó las expectativas y acabó bruscamente con ese esplendor, lo que explica también que los periódicos judeoespañoles de Viena desaparecieran, en las primeras décadas del siglo XX -como señalaremos a continuación".

la comunidad Israelit-española del tiempo de la fundación hasta hoy según datos históricos (Viena).

${ }^{7}$ Díaz-Mas, Los sefardíes, 78-79.

${ }^{8}$ Para más datos sobre dicha institución, véase A. Ayala y S. Von Schmädel, «Identitätsdiskurse und Politisierung der Sepharden in Wien am Beispiel des Studentenvereins Esperanza (1896-1924)», Transversal. Zeitschrift für Jüdische Studien 11.2 (2010), 83-102.

${ }^{9}$ Actualmente es fundamental la siguiente publicación: M. Studemund-HaLévy, C. Liebl y I. Vučina (eds.), Sefarad an der Donau. Lengua y literatura de los sefardíes en tierras de los Habsburgo (Barcelona: Tirocinio, 2013). Para más datos sobre la comunidad de Viena, véanse también los siguientes estudios: I. DE HoYos, «Los judíos españoles en el Imperio Austríaco y en los Balkanes», Boletín de la Real Academia de la Historia 45 (1904), 205-287; N. M. Gelber, «The Sephardic Community in Vienna», Jewish Social Studies 10 (1948), 359-396; Z. LoKer, «La comunidad sefardí de Viena», en H. Méchoulan, 
El periódico ${ }^{10}$ Ilustra Güerta de Historia salió a la luz el 3 nisán 5640 (15 marzo 1880), es decir, en el período que se establece como la etapa de los inicios del periodismo sefardí ${ }^{11}$, aunque precisamente en la ciudad de Viena los principales periódicos salieron a finales del siglo XIX y desaparecieron a principios de la siguiente centuria. Este aspecto se corresponde, además, con la información que aportan Benbassa y Rodrigue: «En Viena, ciudad con una importante comunidad sefardí, los periódicos en lengua judeoespañola empezaron a proliferar en 1860, coincidiendo con la emancipación» ${ }^{12}$.

Ilustra Güerta de Historia estaba dirigida por Šem Tob Semo (18271881), una de las figuras más destacadas dentro de la comunidad sefardí de Viena -de la que llegó a ser presidente-; es considerado uno de los pioneros del periodismo sefardí en Viena y es conocido tanto por ser un hombre de negocios, como por sus labores de difusión de la cultura, ya sea como editor de varias publicaciones periódicas, como por sus facetas de escritor y traductor de numerosas novelas del alemán al judeoespañol. Entre sus publicaciones periódicas destacan: El Coreo de Viena (18611872) -con sus suplementos: El Treśoro de la Caśa (1871) y La Política (1875)-, El Dragomán (1864) e Ilustra Güerta de Historia (1880-1882). Šem Tob Semo nació en Viena, aunque se educó en Sarajevo ${ }^{13}$. En la dé-

Los judíos de España. Historia de una diáspora (1492-1992) (Madrid: Trotta, 1993), 250251. También los trabajos de M. Studemund-Halévy y G. Collin: «Sefarad an der Donau. Sefardische Drucke aus Wien», David. Jüdische Kulturzeitschrift 82/09 (2009), 44-47; «Era una vez... La Komunidad Israelit-espanyola de Vyena», El Amaneser V/61 (2010), 14-17; «Wie Wien zu seinen Sefarden kam. Die wundersame Geschichte des Diego de Aguilar», David. Jüdische Kulturzeitschrift XXII/84 (2010), 36-38.

${ }^{10}$ Aunque nos referiremos a él como 'periódico' lo cierto es nos hallamos, para ser más concretos, ante una especie de colectánea literaria, ya que los contenidos que aquí encontramos no son los habituales en la prensa periódica -textos de información diversa, de opinión, etc.sino, fundamentalmente, material literario de entretenimiento, ya que entre las páginas de esta Ilustra Güerta de Historia se publicaron, por ejemplo, diferentes novelas seriadas.

${ }^{11}$ Sobre las diferentes etapas en que se ha dividido el periodismo judeoespañol véase I. M. Hassán, «El estudio del periodismo sefardí», Sefarad 26 (1966), 229-235 (reseña del libro, en hebreo, de M. D. Gaon, cit. supra), especialmente pág. 230.

${ }^{12}$ E. Benbassa y A. Rodrigue, Historia de los judios sefardíes. De Toledo a Salónica (Madrid: Abada Editores, 2004), 248.

${ }^{13}$ Seguimos los datos que aporta D. Bunis, «Shem Tov Semo, Yosef Kalwo, and Judezmo Fiction in Nineteenth-Century Vienna», en Studemund-Halévy, Liebl y Vučina 
cada de los 50 del siglo XIX se trasladó con su esposa, Blanca Perera, de nuevo a Viena, donde comenzó su exitosa carrera ${ }^{14}$.

Con el periódico Ilustra Güerta de Historia Šem Tob Semo pretendía acercar la cultura, en sus más diversas manifestaciones, a todos sus correligionarios sefardíes, de ahí que entre los contenidos de esta publicación se encuentren «historias anticas judaicas», novelas que se fueron publicando por entregas ${ }^{15}$, historietas curiosas, anécdotas, aforismos, adivinanzas, etc. El propio Semo había afirmado:

Ich begann meine journalistische Tätigkeit mit dem Ziel, die Lust an der Literatur zu wecken, meine Leser für die jüdische Sache zu interessieren, sie über politische und soziale Entwicklungen zu un-

(eds.), Sefarad an der Donau, 39-146: 44-45. Véase también E. Romero, «The Theme of Spain in the Sephardic Haskalah's Literature», en M. LAZAR \& S. Haliczer (eds.), The Jews of Spain and the Expulsion of 1492 (Holline Court, Lancaster: Labyrinthos 1997), 311-327: 316-318.

${ }^{14}$ Para más datos sobre diversos aspectos de la figura de Šem Tob Semo, véanse S. VoN SCHMÄDEL, «Shem Tov Semo. El konde i el Djidyo», Neue Romania 37 [= Judenspanisch XI, 1 y 2] (2007), 177-353; EAdEm, «El léxico en El Konde i el Djidyo de Shem Tov Semo (Viena) y la modernización del español», en W. Busse y M. Studemund-HaLévy, eds., Lexicología y lexicografía judeoespañolas (Berna et al.: Peter Lang, 2011), 167-180; K. ŠMID, «Gaćetero vienés vs. rabino saraylí: el inicio de una polémica», en Díaz-MAS y SÁnchez Pérez (eds.), Los sefardíes ante los retos del mundo contemporáneo, 149158; M. Studemund-Halévy y G. Collin, «Shem Tov Semo - Spuren einer Biographie», David. Jüdische Kulturzeitschrift 83, 12 (2009), 42-43; así como el trabajo ya citado de Studemund-Halévy, «Shem Tov Semo, Sefardi Vienna»; BunIS, «Shem Tov Semo, Yosef Kalwo, and Judezmo Fiction»; y los datos que aparecen en la página Sefardiweb del CSIC: http://www.proyectos.cchs.csic.es/sefardiweb/node/21.

${ }^{15}$ De igual forma que ocurría con las publicaciones periódicas europeas de la época era bastante habitual que la prensa sefardí incluyera novelas -normalmente por entregasentre las páginas de sus periódicos. Véanse, por ejemplo, A. BARQuín, Edición y estudio de doce novelas aljamiadas sefardíes de principios del siglo XX (Bilbao: Universidad del País Vasco, 1997); Romero, La creación literaria, especialmente pág. 226; y, para nuestro caso concreto, pág. 230; C. MARTínEZ-GálvEZ, «La prensa sefardí en Rumanía: contenidos del periódico El Luzero de la Pasensia (Turnu-Severin 1885-1888)», Revista de Filología Románica 26 (2009), 205-227; y E. Rieder-ZelenKo, Novedades de Esmirna. Edición de noticias publicadas en el periódico judeoespañol «La Buena Esperanza» en 1905 (Barcelona: Tirocinio, 2013), especialmente, págs. 45-49. 
terrichten und mit meinen Texten eine Bibliothek an guter Literatur zu schaffen ${ }^{16}$.

Por lo tanto, como había ocurrido con otros muchos editores y redactores de periódicos sefardíes, entre los principales cometidos que se impusieron, a través de las páginas de estas publicaciones, estaban no solo informar e instruir, sino también entretener y acercar todo tipo de cultura y literatura, con especial atención a la secular -de origen occidental, fundamentalmente-. Como veremos más adelante, dentro de estas publicaciones de perfil literario no solo encontraremos poesía, novelas, etc., sino también otro tipo de contenidos, como pueden ser refranes, adivinanzas, chistes, etc. ${ }^{17}$. En este sentido, debemos considerar todas estas materias como elementos integrantes de la cultura, entendida en su sentido más amplio. De este modo podemos llegar a comprender cómo en este tipo de publicaciones se encuentran obras literarias de la que podríamos denominar como «alta cultura», junto con manifestaciones propias y típicas de la cultura popular, e incluso, en ocasiones, tomadas de la tradición oral.

Nuestra atención se va a centrar ahora en los acertijos y adivinanzas que aparecieron en la Ilustra Güerta de Historia. Hemos fijado el corpus en los treinta y tres primeros números de este periódico, distribuidos en dos volúmenes, ya que parece que son los únicos conservados ${ }^{18}$. El primer año íntegro de la Ilustra Güerta de Historia conforma el volumen I: desde desde nisán 5640 (marzo 1880) hasta nisán 5641 (abril 1881). El volumen consta de 12 números. Los diez primeros se publicaron por separado, pero los dos últimos, el 11 y el 12, aparecieron impresos de manera conjunta.

A diferencia de este primer volumen que se encuentra muy bien conservado, el volumen II está bastante deteriorado y se han perdido algunas

${ }^{16}$ Studemund-Halévy y Collin, «Shem Tov Semo - Spuren». Por lo tanto, el hecho de que los lectores se interesen por la causa judía deriva de que haya logrado despertar el interés por la literatura.

${ }^{17}$ En algunos casos, esos chistes insertos en diferentes periódicos sefardíes nos han deparado alguna que otra sorpresa al comprobar que, en realidad, se trataba de antiguas historias y leyendas. Como ejemplo puede verse M. SÁnchez Pérez, «Entre escritura y oralidad: cuentos tradicionales en el periódico sefardí Yerushalayim (1909)», en DíAZ-MAS y SÁnchez Pérez (eds.), Los sefardíes ante los retos del mundo contemporáneo, 193-202.

${ }^{18}$ Hemos manejado reproducción microfilmada de los ejemplares conservados en la Biblioteca Nacional de Israel. 
planas, sobre todo del primer y de los últimos números, que están incompletos. Teniendo en cuenta lo que se ha conservado, el volumen II estaría formado por 11 números -lo más probable, con todo, es que fueran 12 y, de este modo, se cerraría el segundo año completo-. Cabe deducir que este volumen II apareció entre los años de 1881 y 1882, pero no podemos afirmarlo con seguridad.

La cabecera de la Ilustra Güerta de Historia se abría así ${ }^{19}$ : «Aparece cada 15 del mes, doĝe veces al año. Seš plegos de continencia cada número. La aḅonemá por una año adelantado en Viena, 5 florines. Afuera de Viena, 6 florines» ${ }^{20}$. A continuación aparecían los responsables y redactores -de lo que nos ocuparemos más adelante- y, por último, se hacía constar la fecha exacta de publicación, según el calendario gregoriano y el calendario hebreo. La indicación de la fecha desapareció en el volumen II, por lo que no podemos saber la data concreta en la que apareció el periódico.

En sus comienzos, en el volumen I, la publicación mantuvo una periodicidad regular ya que, según el calendario gregoriano, cada número aparecía el día 15 de cada mes, tal y como señalaba el periódico. De este modo, desde el número 1 hasta el 7 el periódico se publicaba el día 15 -desde el mes de marzo hasta septiembre de 1880-. Posteriormente, la periodicidad comenzó a ser irregular y, de este modo, el número 8 apareció el 1 de noviembre de 1880, el 9 el 24 de diciembre de 1880, el 10 el 24 de febrero de 1881 y, por último, los números 11 y 12 salieron impresos conjuntamente el 13 de abril de $1881^{21}$. Como decimos, en el volumen II la indicación de la fecha desapareció y, aunque constaba expresamente que «aparece cada 15 del mes, doĝe veces al año», no sabemos con exactitud si esa periodicidad se cumplió.

\footnotetext{
${ }^{19}$ Para el estudio del grabado que abría la cabecera del periódico Ilustra Güerta de Historia, véase el trabajo de M. Cimelı «La Gartenlaube y las Güertas de Historia», en Studemund-Halévy, Liebl y Vučina (eds.), Sefarad an der Donau, 147-158, donde establece las semejanzas entre la cabecera de una colección de novelas alemana que se titulaba Die Gartenlaube ('pérgola del jardín') y el grabado que aparecía en las Güertas vienesas de Šem Tob Semo, y su reedición en Salónica años después.

${ }^{20}$ El precio de la suscripción se mantuvo igual a lo largo de toda la vida del periódico.

${ }^{21}$ Cabe destacar que los números que aparecieron en 1881 todavía llevan indicación de 1880. Los impresores debieron equivocarse, de ahí que, posteriormente, una mano haya corregido a lápiz o a bolígrafo las fechas en los originales, colocando un 1 encima del 0.
} 
Respecto al volumen I, cada uno de los números contaba con veinticuatro páginas, con la excepción de los números 11 y 12 que, al editarse juntos, sumaban cuarenta y ocho páginas en total. Además, todos los números se paginaron correlativamente, por lo tanto, el primer número comenzó en la página 1 y el último finalizó en la 288. Ello indica claramente la percepción que tenía Šem Tob Semo de publicar volúmenes íntegros, ya que a partir del segundo año, la numeración comienza nuevamente en la página 1 . No obstante, frente a esas veinticuatro páginas que tuvieron todos los números del volumen I, en el II encontramos diferencias, ya que desde el primer número hasta el octavo sí se mantuvieron esas veinticuatro páginas, pero en el noveno y el décimo descendieron a veinte ${ }^{22}$. Esa numeración de páginas corridas cada año indica claramente que Šem Tob Semo concebía los números de su periódico como coleccionables. Una vez coleccionados se podían encuadernar juntos para formar un volumen, práctica más o menos habitual en la prensa del siglo XIX -no solamente sefardí-, como ocurrió, por ejemplo, con otra publicación en judeoespañol: El Luzero de la Pasensia $^{23}$. Cabe destacar, además, que en la última página del volumen I se imprimió un listado con los contenidos que habían ido apareciendo en el periódico, bajo la siguiente indicación: «Contenidos de las historias, poeśías y artículos en el primer año de la Ilustre Güerta de Historia». Como no se han conservado las últimas planas del volumen II no podemos afirmar con seguridad que este mismo hecho se repitiera en el segundo año, pero es muy probable que así fuera.

Respecto a los responsables y editores de la Ilustra Güerta de Historia sabemos que el director del periódico fue -como hemos venido señalandoŠem Tob Semo. En el volumen I, en la cabecera de los periódicos que van del 1 al 7 aparecía la siguiente indicación: «Patrón: Šem Tob b. Šaḅetay

${ }^{22}$ El número 11 no se ha conservado por completo y solamente tenemos 16 páginas, aunque es probable que fueran realmente $20 \mathrm{y}$, posiblemente, lo mismo ocurriría con el número 12 que cerraría el volumen II.

${ }^{23}$ Véanse para este caso: P. DíAZ-MAS y A. BARQuín, «Relaciones entre la prensa española y la prensa sefardí a finales del siglo xIx: el caso del Luzero de la Pasensia», en P. Martín Asuero y K. Gerson Sarhon (eds.), Ayer y hoy de la prensa en judeoespañol (Estambul: Isis, 2007), 10-37; MARTínEZ-GÁLVEZ, «La prensa sefardí en Rumanía». 
Semo y profesor I. Zaksil. Redactor responsable: Adolf de Żemlinski» ${ }^{24}$. A partir del número 8 del volumen I y hasta el número 7 del volumen II, la cabecera cambió y pasó a ser la siguiente: «Patrón: Šem Tob B. Šabetay Semo. Redactor responsaḅle: Wilhelm Schlosberg». Por último, a partir del número 9 del volumen II, todas estas indicaciones desaparecieron y, en su lugar, se señalaba «Las cartas nos sean aderezadas [en judeoespañol] a la redacción El Correo de Viena» [en castellano]. Wien» ${ }^{25}$.

Centrándonos ahora únicamente en las adivinanzas que aparecieron en esta Ilustra Güerta de Historia, cabe destacar que todas ellas se hallaban en las últimas páginas de algunos números. En las últimas planas de esta publicación se incluía, para finalizar el periódico, una sección denominada «Sala de pasatiempo». En ella encontramos noticias curiosas, anécdotas, historietas, etc., y también estos acertijos y adivinanzas.

\section{Sobre ACERTIJOS, ADIVINANZAS Y ENIGMAS}

No queremos ahora adentrarnos en la problemática terminológica para diferenciar adivinanza, acertijo o enigma. Normalmente, las definiciones que encontramos recogidas en diferentes diccionarios emplean como sinónimos 'acertijo' y 'adivinanza'. Así, por ejemplo, en el DRAE el término adivinanza se describe como 'acertijo' y este, a su vez, como 'enigma o adivinanza que se propone como pasatiempo', y es la opinión mantenida por algún autor como Joaquín Díaz ${ }^{26}$.

\footnotetext{
${ }^{24}$ Adolf von Zemlinsky procedía de una familia católica de Viena y, de hecho, fue bautizado en la parroquia católica de San José; sin embargo se integró en la comunidad judía de Viena al casarse con la hija de Šem Tob Semo, Clara Semo -fueron los padres del compositor austríaco Alexander von Zemlinsky-. Como se dice en la Ilustra Güerta de Historia Adolf von Zemlinsky fue redactor responsable de dicha publicación desde el 15 de marzo (3 nisán 5640) hasta el 15 de septiembre de 1880 (11 tišrí 5640). Además de periodista, fue también secretario de la Comunidad turco-israelita de Viena y era escritor de novelas. De hecho Šem Tob Semo tradujo algunas de esas obras del alemán al judeoespañol. Escribió una historia de la comunidad «israelit espanyola» en Viena (1888) (Studemund-Halévy, «Shem Tov Semo, Sefardi Vienna», 319, 320, y 320 n. 5).

${ }^{25}$ La indicación 'Wien' desapareció en los números 10 y 11 del volumen II.

${ }^{26}$ Para el que «la adivinanza o enigma es un juego intelectual, en forma de composición breve en verso o en prosa, por medio del cual un persona propone una pregunta (cuya respuesta ya conoce) en términos ambiguos para que otra intente acertarla. El juego y
} 
Ello contrasta con la posición de José L. Gárfer y Concha Fernández, pioneros en el estudio de estas cuestiones en el ámbito español que distinguen entre acertijos y adivinanzas ${ }^{27}$. En nuestros textos en judeoespañol los editores de Ilustra Güerta de Historia suelen encabezar estos enigmas con el término «endevinas»-de manera mayoritaria- y también, en algunas ocasiones, «demandas y respuestas», sin que exista una diferencia clara entre unas u otras. En cualquier caso, independientemente de la terminología concreta que utilicemos, los acertijos y las adivinanzas han estado ligadas a la tradición y a la cultura de cualquier pueblo desde la Antigüedad. El desciframiento de enigmas ha estado presente desde tiempos remotos en la cultura china, india, griega, romana, germana, egipcia, maya, etc., y tenemos diferentes testimonios en obras cultas de diferentes culturas, aunque los acertijos y adivinanzas han estado muy vinculadas, sobre todo, a la tradición oral. Siguiendo a Francisco Caudet y M. ${ }^{a}$ José Llorens: «El acertijo tiene su origen en Oriente en donde fue no pocas veces la expresión de elevados conceptos que permanecían velados por el misterio y la oscuridad. Ya entre los hebreos desempeñó [...] un papel importantísimo» ${ }^{28}$. Gárfer y Fernández señalaban: «La habilidad para resolver acertijos se consideraba en la antigüedad como la mejor carta credencial de sabiduría» ${ }^{29}$. En nuestra

la ambigüedad son componentes inseparables del género [...] que ha tenido en España cultivadores tan excelentes como Berceo, el Arcipreste de Hita, don Juan Manuel, Juan del Enzina, Sebastián de Horozco, Alonso de Ledesma, Miguel de Cervantes, Cristóbal Pérez de Herrera, Félix Lópe de Vega, Luis de Góngora y otros. Muchas, y no siempre claras, han sido las voces utilizadas para denominar al juego; algunas, como enigma, pregunta o acertijo, tienen un contenido semántico; otras como quisicosa o cosa y cosa se basan en la fórmula inicial con que tradicionalmente se hace la pregunta; las hay, finalmente, que, como adivina o adivinanza combinan ambos modelos», cf. J. DíAz, «Adivinanza», en J. Álvarez Barrientos y M. J. Rodríguez Sánchez de León, Diccionario de Literatura Popular Española (Salamanca: Ediciones Colegio de España, 1997), 16-18, s.v. adivinanza.

${ }^{27}$ En su opinión, «primero fue el acertijo y, cuando este se arropó con el verso, nació la adivinanza. Acertijo y adivinanza coinciden en formular una pregunta ingeniosa, pero diferencian, en la estructura superficial del lenguaje, porque el acertijo se expresa en prosa, y la adivinanza en verso», cf. J. L. GÁRFER y C. FERNÁNDEZ, Adivinancero antológico español (Madrid: Ediciones del Prado, 1994), 7. Desde entonces, la crítica ha mantenido esta distinción.

${ }^{28}$ Apud F. CAUDET y M. J. LloREnS, Los mejores acertijos y adivinanzas ([Madrid]: M. E. Editores, 1995), 7.

${ }^{29}$ J. L. GÁrfer y C. Fernández, Acertijero popular español (Madrid: Fundación Banco Exterior, 1989), 11. 
sociedad actual es frecuente asociar las adivinanzas y los acertijos con el proceso de enseñanza-aprendizaje en los niños, sin embargo sabemos que pertenecen al bagaje cultural del folklore literario de los pueblos, ya que, desde siempre, gracias a ellos se estimula la curiosidad, ayudan a fomentar una actitud crítica frente al mundo que nos rodea. El objetivo primordial de los acertijos ha sido habitualmente el de entretener, el de servir como juego, pero, eso sí, juego intelectual, ya que favorecen el aprendizaje, ayudan a potenciar las habilidades lógicas y asociativas del individuo y, además de todo ello, contribuyen al mantenimiento de la literatura oral, de la tradición y la cultura popular.

Como señalábamos más arriba, examinando este y otros periódicos sefardíes cuyos contenidos se describían en muchas ocasiones como «literarios» observamos que esa percepción de la literatura, en sentido estricto, y de la cultura, en un sentido más amplio, permitía que en estas publicaciones no solo aparecieran géneros típicamente pertenecientes a la literatura «mayor», como puede ser la poesía o la inclusión de novelas, sino que también encontraremos historietas, refranes, chistes, acertijos, etc., es decir, elementos pertenecientes al folklore literario. En el caso de los últimos, casi todos ellos suelen ser breves y fáciles de recordar, por lo que se estimula la imaginación.

Como ocurre con otros campos del folklore cultural y literario, como pueden ser chistes, trabalenguas, etc., las investigaciones en torno a los acertijos y las adivinanzas no son muy numerosas, aunque cada vez contamos con más colecciones y antologías. En el caso español, como ya hemos señalado, Gárfer y Fernández fueron los pioneros en el estudio y recopilación de acertijos y adivinanzas -cultos y populares- a partir de la década de los ochenta del siglo XX -con posterioridad les han seguido otros estudiosos, como veremos más adelante-.

En el caso de la cultura sefardí, Samuel G. Armistead y Joseph H. Silverman ya señalaron en 1982 que «de todas las formas diferentes de la literatura oral folklorika en Djudeo-Espanyol, las endevinas son las ke aven sido menos arrekojidas de la tradision i menos estudiadas» ${ }^{30}$. Posteriormente, señalaban «las adivinanzas constituyen sin duda el género

${ }^{30}$ S. G. Armistead y J. H. Silverman, «Las endevinas djudeo-espanyolas», Aki Yerushalayim 3/12 (1982), 11-14: 11. 
folk-literario más desatendido de la tradición judeo-española» ${ }^{31}$ y en 1998 seguían afirmando que las adivinanzas eran «la oveja más negra de todos los tipos genéricos» ${ }^{32}$. Siguiendo estos estudios, parece que la colección más antigua y extensa de adivinanzas judeoespañolas se encuentra incluida en el libro de Max A. Luria sobre el judeoespañol de Monastir (1930) donde aparecían recogidas un total de treinta y cuatro adivinanzas ${ }^{33}$.

Respecto al origen de los acertijos judeoespañoles, Armistead y Silverman aseguran que unos son de origen plenamente hispánico, mientras que otros parece que fueron integrados en el repertorio sefardí después de la diáspora $\mathrm{y}$, por tanto, los tomaron fundamentalmente de la cultura de los pueblos de Turquía y los Balcanes. Con todo, aseguraban, el problema era difícil, ya que en algunos casos parece prácticamente imposible que lleguemos a conocer su origen ${ }^{34}$. Ya lo había señalado décadas antes Archer Taylor -gran conocedor de la literatura enigmática- respecto al estudio de las adivinanzas en cualquier cultura:

The problems in the study of riddles fall under three heads: the collection of riddles, the description of the stylistic peculiarities of riddles, and the history of the origins and the use of riddles. The order in which I have named these classes of problems is the order of their difficulty, but when our collections are larger and are better indexed, studies in the style and history of riddles will be less difficult than now ${ }^{35}$.

En 1950, Michael Molho, al tratar de los usos y costumbres de los judíos sefardíes de Salónica, señalaba sobre las adivinanzas: «Cuando el tiempo era inclemente, los pequeños judíos se quedaban en casa en

${ }^{31}$ S. G. Armistead y J. H. Silverman, «Adivinanzas judeo-españolas de Turquía: los 'enigmas' del Rabino Měnaḥēm 'Azôz», Philologica Hispaniensia in honorem Manuel Alvar (Madrid: Gredos, 1983), vol. I (Dialectología), 81-92: 81.

${ }^{32}$ S. G. Armistead y J. H. Silverman, «Nueve adivinanzas de Estambul (Colección Milwitzky)», Sefarad 58 (1998), 31-60: 32.

${ }^{33}$ M. A. LuRIA, A Study of the Monastir Dialect of Judeo-Spanish Based on Oral Material Collected in Monastir, Yugo-Slavia (New York: [s.n], 1930 [reimpr. Revue Hispanique 79/176 (1930), 323-583]).

${ }^{34}$ Armistead y Silverman, «Las endevinas djudeo-espanyolas»; véase también su «Nueve adivinanzas de Estambul»).

${ }^{35}$ A. TAYLOR, «Problems in the Study of Riddles», Southern Folklore Quarterly 2 (1938), 1-9: 1. 
terlikes (palabra turca que significa calzones de paño [...]) calentándose, frioleros, en torno al fogarero. Para matar el tiempo poníanse adivinanzas [...]» ${ }^{36}$. Posteriormente en 1963, David Elnecavé, en un estudio sobre el folklore de los sefardíes de Turquía, afirmaba que las adivinanzas «constituían una de las más estimadas diversiones en las reuniones íntimas familiares o sociales» ${ }^{37}$; sin embargo, con los datos que disponemos en la actualidad, el número de acertijos judeoespañoles que conocemos superan mínimamente la centena.

En total contamos con los siguientes estudios y/o recopilaciones ${ }^{38}$ : en 1930 Max A. Luria recogió 34 adivinanzas de la tradición de Monastir (Yugoslavia) ${ }^{39}$; en 1948, Abraham Galante recopiló 47 acertijos en su apéndice sobre la historia de los judíos de Grecia ${ }^{40}$; posteriormente, Michael Molho, en 1950, incluyó una adivinanza en su libro Usos y costumbres de los sefardíes de Salónica ${ }^{41}$; David Elnecavé, en un estudio de 1963, incluyó 3 adivinanzas procedentes del folklore de Turquía ${ }^{42}$; en 1982, Samuel G. Armistead y Joseph H. Silverman, en un acercamiento a las «endevinas» judeoespañolas, incluyeron 7 adivinanzas sefardíes ${ }^{43}$; ellos mismos, en 1983, publicaron 9 adivinanzas tomadas de una breve colección recopilada por el rabino Menahem 'Azoz de Turquía ${ }^{44}$; pos-

${ }^{36}$ M. Molno, Usos y costumbres de los sefardíes de Salónica (Madrid: CSIC, 1950), 141-142.

${ }^{37}$ D. ElneCavé, «Folklore de los sefardíes de Turquía», Sefarad 23 (1963), 325-334: 326.

${ }^{38}$ En 1982 Samuel G. Armistead y Joseph H. Silverman animaban a enviar «endevinas» -así como otras manifestaciones del folklore en judeoespañol: cantigas, proverbios, etc.a los lectores de la revista Aki Yerushalayim. Queda pendiente para un estudio posterior recopilar las posibles adivinanzas y acertijos que allí se hayan podido publicar.

${ }^{39}$ LURIA, A Study of the Monastir Dialect, 88-90.

${ }^{40}$ A. Galante, Appendice à l'Histoire des Juifs de Rhodes, Chio, Cos, etc. (Estambul: Kagit ve Basim Isleri A. S., 1948), 22-24.

${ }^{41}$ Molho, Usos y costumbres de los sefardíes de Salónica, 142.

${ }^{42}$ ElneCavé, «Folklore de los sefardíes», 326-327.

${ }^{43}$ Armistead y SiLVERMan, «Las endevinas djudeo-espanyolas», incluyen también adivinanzas en otros idiomas -español, turco, griego, etc.-, así como algunas del profesor Luria.

${ }^{44}$ Armistead y Silverman, «Adivinanzas judeo-españolas de Turquía». Aquí, los autores -como ellos mismos señalan- pretenden «hacer asequibles al hispanismo la colección del R. 'Azôz ofreciendo una transliteración en letras latinas de las adivinanzas» (pág. 82), que Menahem 'Azoz había publicado en 1945 en hebreo con el nombre de Hidot ('Enigmas') en la revista Hed ha-Mizrạ̣ ('Eco de Oriente'). 
teriormente, Samuel G. Armistead publicó dos adivinanzas de origen griego ${ }^{45}$; más adelante, de nuevo Armistead y Silverman estudiaron 9 adivinanzas inéditas ${ }^{46}$, recogidas por el profesor William Milwitzky en diversas entrevistas que realizó a judíos de Belgrado, Bucarest, Sofía, Plovdiv, Salónica, Jíos, Rodas y Estambul entre 1898 y 1899; en 1999, David Bunis añadió una adivinanza ${ }^{47}$; y, por último, en 2006, Tamar Alexander aportó 4 adivinanzas más ${ }^{48}$. En total, teniendo en cuenta la suma de acertijos y adivinanzas contenidos en estos estudios que hemos señalado, el número asciende a 117.

\section{TEXTOS DE LOS ACERTIJOS Y ADIVINANZAS: EDICIÓN ${ }^{49}$}

[1] Cuando yo me daño, tú te aprovechas, y cuando me matas, es mi provecho. ¿Quén so yo?

(La candela) [vol. I, núm. 1, pág. 24a].

[2] Tu statuta se para delantre de mí, tus caras ríen a mí. Yo estó parado delantre de ti y no veo a ti, y con todo esto tu altigüeźa es por mí y te enbelecas con namoramiento a mí. Yo te digo: que so muermo ${ }^{50}$,

${ }^{45}$ S. G. Armistead, «Two Judeo-Spanish Riddles of Greek Origin», Laographia 33 (1982-1984), 169-175.

${ }^{46}$ Armistead y Silverman, «Nueve adivinanzas de Estambul».

${ }^{47}$ D. Bunis, Voices from Jewish Salonika. Selections from the Judezmo Satirical Series Tio Ezrá i su Mujer Benuta and Tio Bohor i su Mujer Djamila (Jerusalem/Salonica: Misgav Yerushalayim/The National Authority for Ladino/The Ets Ahaim Foundation of Thessaloniki, 1999).

${ }^{48}$ Tamar Alexander, en un estudio sobre las adivinanzas judeoespañolas, afirmaba haber recopilado ella misma 10 adivinanzas más. Sin embargo, en su trabajo solamente incluye cuatro de ellas, ya que su estudio no se propone consignar todas, sino realizar un análisis de «l'art de la devinette dans la culture judéo-espagnole, d'en déterminer les diverses formes, d'en définir les caractéristiques ainsi que la place et la fonction dans le groupe socioculturel considéré» (pág. 142), en T. AleXANDER, «Komo puede ser? L'art de la devinette dans la culture judéoespagnole», Yod: Revue des études hébraïques et juives 11-12 (2006-2007), 141-163.

${ }^{49}$ Aclaramos en el glosario el significado de aquellas palabras que puedan ofrecer alguna dificultad al lector culto. La numeración de estos acertijos y adivinanzas es nuestra teniendo en cuenta el orden en el que aparecieron publicados en la Ilustra Güerta de Historia.

${ }^{50}$ En el texto se lee claramente «muermo», pero cabe la posibilidad de que hubiesen querido decir «tuerto». 
mudo y ciego y solo un embeleco ex́iste de ti a mí. ¿Quén so yo? (El spejo) [vol. I, núm. 1, pág. 24a].

[3] Una compañía de hombres jugaron la noche entera, a la fin todos ganaron. ¿Cómo es esto? ${ }^{51}$

(Una banda de múśica que fue pagada) [vol. I, núm. 1, pág. 24a].

[4] Yo no tengo pies, coro con grande prisa día y noche y con todo esto no salgo de mi cama. ¿Quén so?

(El río de agua) [vol. I, núm. 2, pág. 48b].

[5] Yo tengo un buraco, yo hago un buraco y paso por dientro de él. ¿Quén so?

(La alguj́a) [vol. I, núm. 2, pág. 48b].

[6] Cuando tengo la tripa llena me amas y cuando está mi tripa vaćía te aleǰas de mí. ¿Quén so?

(La soḅa ardiendo en envierno) [vol. I, núm. 2, pág. 48b].

[7] El que me vee, para aquel no es, el que tiene menester, no paga por ello moneda y el que me hinche, no lo haće con veluntad. ¿Quén so? (El entero [québer]) [vol. I, núm. 2, pág. 48b].

[8] Chico o grande so solo la largura de un pie. ¿Quén so? (El zapato) (o chiźmeź) [vol. I, núm. 2, pág. 48b].

[9] Mi buraco es chico, es lišo y limpio. ¿Quén so? (La alguja) [vol. I, núm. 2, pág. 48b].

[10] Yo no tengo pies para caminar, solo para estar en pies y sobre mi halda tienes tú en diversos laboros repośo. ¿Quén so?

(La silla de asentar) [vol. I, núm. 2, pág. 48b].

[11] Pies tengo y no camino, empero me detengo sobre mis pies y sobre mis rodillas topas tu repośo. ¿Quén so?

(La silla para asentar) [vol. I, núm. 3, pág. 72a].

\footnotetext{
${ }^{51} \mathrm{El}$ acertijo se basa en un juego de palabras con las dos acepciones del verbo 'jugar': 'jugar un juego' y 'tocar un instrumento'.
} 
[12] Yo so relumbrante, hermośa y limpia por afuera, empero sućia por aentro. ¿Quén so?

(La nieve) [vol. I, núm. 3, pág. 72a].

[13] Yo estó encargada y bien peśgada, vengo sin pies sobre mi tripa y coro con todo esto tan presto como el viento. ¿Quén so?

(La nave) [vol. I, núm. 3, pág. 72b].

[14] Con todo que mi luenga no habla, con todo esto me es muy menesterośo. Yo sé lo que es derecho y lo que no es derecho, y enveźo lo justo a la ǵente. ¿Quén so?

(La balanza) [vol. I, núm. 3, pág. 72b].

[15] En el aver aṿolo, sobre la tiera estó echada, sobre los árboles asentada, en las manos sudada, en las soḅas deretida, en la agua ahogada. ¿Quén so?

(La nieve) [vol. I, núm. 3, pág. 72b].

[16] ¿Quén arecodra a sus devdores diversas većes al día?

(El hambre y la sed) [vol. I, núm. 3, pág. 72b].

[17] ¿Ónde no tienen las mares y los ríos agua, ónde no tienen las civdades cośas y ónde no tienen los campos frutos?

(Sobre la carta) [vol. I, núm. 3, pág. 72b].

[18] ¿Cuála es la más grande riqueźa?

(La salud) [vol. I, núm. 3, pág. 72b].

[19] ¿Cuála manzana tiene más grande valor?

(La manzana del ojo) [vol. I, núm. 3, pág. 72b].

[20] ¿Ónde se bebe el vino más?

(Debajo de la nariź) [vol. I, núm. 3, pág. 72b].

[21] En la mañana camino sobre cuatro, la medio día camino sobre dos y la tadre camino sobre tres. ¿Qué crianza so yo? (La persona: la criatura cuando empieza a caminar, camina sobre pies y manos, cuando se engrandece camina sobre sus pies y cuando 
se envejece camina asufrido sobre un palo) [vol. I, núm. 3, pág. 72b].

[22] Sobre la cabeza so yo una arma pericolośa y en la boca so un llamador, comandador y saludador. ¿Quén so yo?

(El cuerno $)^{52}$ [vol. I, núm. 8, pág. 192b].

[23] ¿Por qué son muchas bodas celebradas a las calladas?

(Para modre que la šematá viene después) ${ }^{53}$ [vol. I, núm. 8, pág. 192b].

[24] ¿Qué haće una muchacha cuando tiene 19 años?

(Entra en los 20 años) [vol. I, núm. 8, pág. 192b].

[25] ¿Qué[n] fue por unos cuantos días solo más mancebo que su madre? (Adam Arišón) ${ }^{54}$ [vol. I, núm. 8, pág. 192b].

[26] ¿Cuándo son los pešcados chicos muy estimados?

(Cuando no hay grandes) [vol. I, núm. 8, pág. 192b].

[27] ¿Cuála planta es devista conocida de los ciegos?

(Los punchones) ${ }^{55}$ [vol. I, núm. 8, pág. 192b].

[28] El probe lo come con el pan y el ric[o] lo binea. ¿Quén es esto?

(Carne de caballo) [vol. I, núm. 8, pág. 192b].

[29] ¿Cuál caballo vee detrás como de delantre?

(El caballo ciego) [vol. I, núm. 8, pág. 192b].

\footnotetext{
${ }^{52}$ Alude a los cuernos de los animales -que son, en efecto, sus armas- y al šofar, instrumento hecho con el cuerno de un carnero que se toca para anunciar el inicio del šabat y se tañe en determinadas ocasiones de los oficios litúrgicos sinagogales. Por eso en el acertijo se dice que es «llamador, comandador y saludador».

${ }^{53} \mathrm{El}$ acertijo tiene un doble significado gracias al sentido de šematá que significa 'excomunión', pero también 'barullo, jaleo, algarabía'.

${ }^{54}$ Es decir, 'Adán el primer hombre'; quizá dice que fue solamente durante unos días más joven que su madre porque su «madre» era la tierra, de la que fue formado, y Adán empezó a envejecer enseguida, mientras que la tierra no envejece.

${ }^{55}$ Punchones significa 'púas, espinas'; por lo tanto, la planta aludida es el espino, que los ciegos identifican inmediatamente al tacto, porque pincha.
} 
[30] ¿Quén es más de un hombre de honor? (Dos hombres de honor) [vol. I, núm. 8, pág. 192b].

[31] A mí me echan por los muladares y me pega[n] con los pies, me muelen en el molino y me haćen masa y a a la [sic] fin vengo en manos del estudiando $[\mathrm{sic}]$ y por mi cavśa se asabenta él y muchos se enriquecen con mí. ¿Quén so?

(El trapo que se haće con eo papel $)^{56}$ [vol. I, núm. 8, pág. 192b].

[32] ¿Cuála persona no viste camiśa?

(El que no la tiene) [vol. I, núm. 8, pág. 192b].

[33] Tengo un leño con 12 ramas y en cada rama hay 4 culebías y en cada culebía hay 7 güevos. ¿Quén so yo?

(El año, los meśes, las semanas y los días) [vol. I, núm. 9, pág. 214b].

[34] ¿Cuálo está en la agua siempre y no se pudre?

(La luenga) [vol. I, núm. 9, pág. 214b].

[35] Yo no tengo boca, empero digo a todos el cosur que tiene sin que se arabie. ¿Quén so yo?

(El espejo) [vol. I, núm. 9, pág. 214b].

[36] De presto que so tres me detiene, de mi boca core miel y tósego, yoz no tengo empero cuando hablo se oe por todas las partes del mundo. ¿Quén so yo?

(La péndola) [vol. I, núm. 9, pág. 214b].

[37] Dos de mi cabeza formea una punta deśmolada, dos formea dos aníos, empero en medio está metido un clavo. ¿Quén so yo?

(La tijera) [vol. I, núm. 9, pág. 214b].

\footnotetext{
${ }^{56}$ Recuérdese que el papel se hacía artesanalmente con trapos mojados y macerados, que se molían para hacer una pasta, de la que luego se hacían los pliegos. Por tanto, lo que está describiendo el acertijo es el proceso de fabricación del papel a partir de trapos: los que se tiran -es decir, van al muladar o basurero-, se ponen en remojo y se pisan -me pegan con los pies-, luego se muelen y se hace una pasta, y de ello se hace el papel que llega a manos del que estudia y, gracias a ello, aprenden los estudiantes y en todo el proceso, desde la fabricación hasta el estudio, muchos se benefician.
} 
[38] ¿Lo qué tienes en ti y no lo consientes?

(El nombre) [vol. I, núm. 9, pág. 214b].

[39] ¿Lo qué no puedes meter que se esté en el clavo ${ }^{57}$ ?

(El güevo) [vol. I, núm. 9, pág. 214b].

[40] Hay dos hermanas en el mundo, la una blanca y clara, y la otra preta y escura, y se covean por el mundo largo y no se pueden alcanźar. ¿Quén son?

(El día y la noche) [vol. I, núm. 9, pág. 214b].

[41] El cuerpo me meten en caśa y la cabeza me dejan afuera. ¿Quén so yo?

(El clavo) [vol. I, núm. 9, pág. 214b].

[42] Son cuatro hermanas prestośas que el día entero coren y no se alcanzan. ¿Cuálas son?

(Las ruedas de el caro) [vol. I, núm. 9, pág. 214b].

[43] Blanca y encalada, / cuando aborecida, cuando amada; / el enverán no queren veerla / y el envierno enpezan aḅrasarla. / ¿Quén so yo? (La soḅa) [vol. I, núm. 9, pág. 214b].

[44] Puedes fuír de ella muy bueno, empero todo viene adetrás de ti. (La solombra) [vol. I, núm. 9, pág. 214b].

[45] Dos palabras ex́isten en el mundo, las cualas pueden destruir y matar. ¿Cuálas son?

(Fanatiśmo y aḅoreción) [vol. II, núm. 1, pág. 24b].

[46] La madre de todas las creaciones es la de onde yo vengo y a mí me topas cerca en cada lugar, sobre meśas de ricos y de probes. ¿Quén so?

(El cartófel) [vol. II, núm. 3, pág. 72b].

${ }^{57}$ En el texto se lee 'clavo'. Probablemente se trata de una errata por 'cabo', es decir, 'extremo': el huevo no se puede poner de manera que se sostenga sobre uno de sus extremos. 
[47] En cada meśa y en cada coćina so yo un musafir; con todo esto no me contratan de musafir, me aroban mi bien, se saborean con yo sus comidas y cuando me ponen en la agua me hago un montón. ¿Quén so?

(La sal) [vol. II, núm. 3, pág. 72b].

[48] El doliente me ama y el sano me aborece, manos de sabios me haćen y en manos de haćinos vengo. Cada persona me conoce y al que no me conoce le sea dicho qué so.

(La melećina) [vol. II, núm. 3, pág. 72b].

[49] Si en mil baños me enbañas y con mil jabones me lavas, siempre quedo preto. ¿Quén so?

(El moro) $)^{58}$ [vol. II, núm. 3, pág. 72b].

[50] El que me vee es ciego y el [que] me oye es sordo. ¿Quén so?

(La palabra «Nada» ${ }^{59}$ ) [vol. II, núm. 3, pág. 72b].

[51] Con los pies so peśado y con todo esto de todos so preciado. ¿Quén so?

(La piedra) [vol. II, núm. 3, pág. 72b].

[52] Hay diez ramicas en dos ramos, los cuales crecen en un árbol y todo artificiośo que se vee en el mundo son los frutos de estas ramicas y de estos ramos. ¿Cuálos son?

(Los dos brazos y los diez dedos) [vol. II, núm. 3, pág. 72b].

[53] Mi valor es chica, con todo so yo amado de las personas. ¿Quén so? (El solde) [vol. II, núm. 3, pág. 72b].

[54] Yo no so bivo y con todo esto puedo hablar con el cercano y lejano. ¿Quén so?

(La péndola) [vol. II, núm. 3, pág. 72b].

\footnotetext{
${ }^{58}$ Recuérdese que el término 'moro' procede de la palabra latina maurus y esta, a su vez, de la griega máuros, que significaba 'negro' o 'moreno'.

${ }^{59}$ Transcribimos en mayúscula ya que en el texto aparece entrecomillada y en letra merubá en tamaño mayor.
} 
[55] So un mancebo deśrepośado / en un lugar no es mi estado, / coro y salto sobre piedra y palo. / Para uno bueno, para otro malo, / también tengo mala fama, / que nunca duermo en mi cama.

(La ola de la mar) [vol. II, núm. 5, pág. 120a].

[56] So un rey sin reinado, sin riqueza y sin soldados, no moro en palacio de mármor y no de palo, no como gaínas asadas y confites, me mantengo de loque topo y mi cuerpo no está cubrido con paños de seda, cadifé o stopa. ¿Quén so?

(El león) [vol. II, núm. 5, pág. 120a] ${ }^{60}$.

\section{Acertijos y adivinanzas en la Ilustra GÜERta de Historia: PARALELOS EN LA TRADICIÓN HISPÁNICA Y SEFARDÍ}

La colección de acertijos y adivinanzas que el periódico Ilustra Güerta de Historia incluyó entre sus páginas asciende a cincuenta y seis, por lo que viene a incrementar en casi un $50 \%$ el corpus de adivinanzas sefardíes conocidas ${ }^{61}$. Después de revisar esos 117 acertijos sefardíes que conservamos gracias a los estudios de Luria, Galante, Molho, Elnecavé, Bunis, Alexander, y Armistead y Silverman sorprendentemente solo hemos encontrado tres que coincidieran con los de nuestro corpus. Se trata del número 21 y, en menor medida, los números 15 y 41, porque la formulación es bastante distinta. Comparando nuestro repertorio con los acertijeros españoles que hemos consultado existen semejanzas también con nuestros números 21,15 y 33 ; y en menor medida -porque la formulación es ya muy distinta- con nuestros números 2 y 35 (ambos hacen referencia al espejo), 43 y 44.

\footnotetext{
${ }^{60}$ Respecto a los epígrafes que encabezaban los apartados, aparecieron como «endevinas» los números 1-2, 4-15, 33-56, y como «demandas y repuestas» 3, 16-32. Son, además, «treślado de la lingua rumena del señor Eliyahu Hayim en Bucarest» los números 33-44.

${ }^{61} \mathrm{Si}$ seguimos las indicaciones de concretar la adivinanza como enigma en verso y el acertijo en prosa, debemos afirmar que nuestra colección incluye: a) durante el primer año de la publicación, es decir, en el volumen I se recogieron cuarenta y tres acertijos y una adivinanza (núm. 43); b) en el volumen II aparecieron nueve acertijos más y una adivinanza (núm. 55).
} 
Respecto al acertijo número 21 , en nuestro corpus se cita de esta forma:

En la mañana camino sobre cuatro, la medio día camino sobre dos y la tadre camino sobre tres. ¿Qué crianza so yo?

(La persona: la criatura cuando empieźa a caminar, camina sobre pies y manos, cuando se engrandece camina sobre sus pies y cuando se envejece camina asufrido sobre un palo).

Luria $^{62}$ lo recoge así: «La mañane camine cun catru pies, la meyudíe cun dos, la tadri cun tres. (Il ombri = niñu, mansevu, vieju)». Y Armistead y Silverman ${ }^{63}$ de la siguiente manera: «La maniana kamina kon kuatro pies / La meyodia kon dos / La tadre kon tres». Estos autores aseguraban sobre este acertijo que se conocía desde hacía muchos siglos y en muchos países, como por ejemplo en Grecia y en España. En efecto, se trata de una de las adivinanzas populares más conocidas. De hecho Gárfer y Fernández recogen el acertijo y cinco adivinanzas ${ }^{64}$ :

a) Acertijo:

-¿Cuál es el animal que por la mañana anda con cuatro pies, a mediodía con dos y por la tarde con tres? [...]

b) Adivinanzas populares:

¿Qué animal es el que anda / de mañana a cuatro pies, / a mediodía con dos / y por la tarde con tres. // Soy un animal que viajo / de mañana a cuatro pies, / a mediodía con dos /y por la tarde con tres. // Un animal /que, de nuevo anda en cuatro pies, /de mediano en dos / y de viejo en tres. // ¿Qué es, qué es: /primero anda en cuatro pies, /después en dos /y luego en tres? // Anda sobre cuatro pies, / irá después sobre dos, / y más tarde sobre tres. ¿¿No adivinas ya quién es?

Bermejo Meléndez señala «Esta es una adivinanza popular creada a partir del mito y del enigma de Edipo». La Esfinge de Tebas tenía aterro-

${ }^{62}$ LURIA, A Study of the Monastir Dialect, 411.

${ }^{63}$ Armistead y Silverman, «Las endevinas djudeo-espanyolas», 13.

${ }^{64}$ GÁRFer y FernándeZ, Acertijero popular, 28. 
rizada a toda la población y devoraba a todos aquellos que no acertaban los enigmas que les planteaba; sin embargo, la Esfinge planteó este acertijo a Edipo, quien lo acertó: «¿Cuál es el ser que tiene cuatro pies por la mañana, dos al mediodía y tres por la noche, pero que, contrariamente a la generalidad de los seres existentes, es tanto menos rápido cuantos más pies utiliza al caminar?» ${ }^{65}$.

Respecto al acertijo número 15, que se refiere a la nieve, en nuestro corpus aparece formulado de esta manera: «En el aver aỵolo, sobre la tiera estó echada, sobre los árboles asentada, en las manos sudada, en las soḅas deretida, en la agua ahogada. ¿Quén so?». Luria recoge: «Un pášaru sin ales abuló, in un árvul sin rames apuzó. / Vieni un ombri sin pies y sin manus lu tumó» ${ }^{66}$. Como decíamos, la formulación cambia bastante y ambas formulaciones se parecen especialmente al comienzo, pero no al final. Parecida también aparece en otros corpus castellanos: «Vuela en el aire, yace en la tierra, se posa sobre los árboles, anda en la mano, se deshace en el horno y se ahoga en el agua. ¿Quién es?» ${ }^{67}$; «Vuela en el aire, / pace en la tierra, / se posa en los árboles, / anda en la mano, / se deshace en el horno / y se ahoga en el agua» ${ }^{68}$.

Por su parte, el número 41 se refiere al clavo y aparece en nuestro corpus así: «El cuerpo me meten en caśa y la cabeza me deǰan afuera. ¿Quén so yo? (El clavo)», mientras que el que recoge Luria se formula de este modo: «Um pretu 'stá inclavadu a la foye. Sólu la cavese si la veyi» ${ }^{69}$. Comienzan, por tanto, a aparecer unas variantes que, al referirse al mismo objeto, la idea que encierran es semejante, pero la formulación difiere ya bastante ${ }^{70}$.

${ }^{65}$ B. Bermejo Meléndez, Adivinanzas y acertijos (Alcobendas, Madrid: LIBSA, 2010), 33, núm. 106. Véase también lo que dice al respecto AleXAnder, «Komo puede ser?», 160-161.

\footnotetext{
${ }^{66}$ LURIA, A Study of the Monastir Dialect, 411.

${ }^{67}$ GÁRFER y FernándeZ, Acertijero popular, 242.

${ }^{68}$ B. Bermejo Meléndez, Adivinanzas y acertijos, 88, núm. 477.

${ }^{69}$ LuRIA, A Study of the Monastir Dialect, 412.

${ }^{70}$ Curiosamente, en las antologías españolas que hemos consultado existen diversos acertijos y adivinanzas relativas al clavo, pero ninguna se parece a la nuestra.
} 
Respecto a los acertijeros españoles que hemos consultado ${ }^{71}$, aparte de los que ya hemos analizado, solamente hemos encontrado uno que sea prácticamente idéntico al que aparece en nuestro repertorio. Se trata del número 33: «Tengo un leño con 12 ramas y en cada rama hay 4 culebías y en cada culebía hay 7 güevos. ¿Quén son yo? (El año, los meśes, las semanas y los días)». Caudet y Llorens lo recogen por partida doble ya que es un acertijo popular dentro de la tradiciones castellana y catalana. En el primer caso aparece formulado de esta manera: «Un árbol con doce ramas, / cada rama cuatro ramitas y / en cada ramita siete brotes / con su nombre diferente». No consignan, sin embargo, la versión en catalán, pero la traducen del siguiente modo: «Un árbol con doce ramas, / cada una tiene un nido, / cada nido siete pájaros / y cada cual su apellido» ${ }^{72}$. Con esta última formulación aparece también recogida en la obra de Pedro C. Cerrillo ${ }^{73}$. Belén Bermejo Meléndez también lo incluye en su antología, pero con distinta formulación: «¿Cuál es el árbol que tiene doce ramas / y cada rama tiene su nombre? / Como no me lo aciertes, / no eres hombre» ${ }^{74}$. No obstante, Rafael Hidalgo y Beatrice Parisi en su Diccionario de enigmística señalaban lo siguiente en relación a esta adivinanza: «Resulta curioso que muchas adivinanzas de la tradición oral se encuentren, con pequeñas variantes, en distintas lenguas y dialectos, en especial en el área de las lenguas romances» ${ }^{75}$.

Menos parecidos son ya los que señalamos a continuación. El número 43 de nuestro corpus, referido a la estufa, reza así: «Blanca y encalada, / cuando aḅorecida, cuando amada / el enverán no queren veerla / y el envierno enpezan aḅrazarla. / ¿Quén so yo?». Belén Bermejo recoje lo siguiente: «En invierno se busca porque da calor, / en verano estorba y se echa al rincón» ${ }^{76}$.

${ }^{71}$ GÁRFER y FERNÁNDEZ: Acertijero popular; Adivinancero antológico; Acertijero antológico. CAudet y Llorens, Los mejores acertijos; Bermejo Meléndez, Adivinanzas; P. C. Cerrillo, Adivinanzas Populares Españolas (Estudio y Antología) (Cuenca: Ediciones de la Universidad de Castilla-La Mancha, 2000). M. T. Miaja y P. C. Cerrillo, Sobre 'zazaniles' y 'quisicosas': estudio del género de la adivinanza (Cuenca: Ediciones de la Universidad de Castilla-La Mancha, 2011).

${ }^{72}$ Caudet y Llorens, Los mejores acertijos, 25, núm. 8; y 110, núm. 52.

${ }^{73}$ Cerrillo, Adivinanzas populares españolas, 137, núm. 260.

${ }^{74}$ Bermejo Meléndez, Adivinanzas, 48, núm. 210.

${ }^{75}$ R. Hidalgo y B. Parisi, Diccionario de enigmística (Barcelona: Octaedro, 2005), 10.

${ }^{76}$ Bermejo Meléndez, Adivinanzas, 58, núm. 278. 
El número 44 de nuestro repertorio: «Puedes fuír de ella muy bueno, empero todo viene adetrás de ti. (La solombra)» frente a estas versiones castellanas: «Nunca podrás alcanzarme, / por más que corras tras mí, / y aunque quieras retirarte / siempre iré yo junto a ti» ${ }^{77}$; «¿Qué cosa es aquella que si la persigues huye y si huyes te persigue?» ${ }^{78}$ que, poseen similitudes, pero la formulación es ya muy distinta.

Y menos parecidos aún, son nuestros acertijos referidos al espejo (números 2 y 35) con la formulación siguiente que hemos encontrado en castellano: «Soy liso y llano en extremo, / y aunque me falta la voz, / digo en su cara a cualquiera / la más leve imperfección; / contesto al que me pregunta / sin lisonja ni aflicción; / si la misma cara pone, / la misma le pongo yo» ${ }^{79}$.

Por último, tenemos semejanzas de diferentes tipos. Por ejemplo, en nuestro repertorio tenemos el siguiente acertijo (30): «Quén es más de un hombre de honor? (Dos hombres de honor)»; en la tradición castellana encontramos formulaciones como las siguientes: «¿Quién gruñe más que un cerdo? (Dos cerdos)»o, por ejemplo, «¿Cuál es la cosa que alumbra más que una vela? (Dos velas) ${ }^{80}$. Por lo tanto, en estos últimos casos encontramos semejanzas entre los acertijos, porque encierran una misma idea y recurren al mismo procedimiento humorístico, pero no coinciden las formulaciones.

Cabe señalar, por otro lado, que sí hemos encontrado similitudes entre las adivinanzas registradas en la tradición sefardí y la castellana, y que no aparecen recogidas en este repertorio de la Ilustra Güerta de Historia. Así, solamente por poner un ejemplo, para referirse al cubo de agua, Max A. Luria, en la tradición judía yugoslava había recogido el siguiente acertijo: «Provi abaše, ricu asuvi» ${ }^{81}$; Galante en la griega: «Abassa riendo y subi llorando» ${ }^{82}$; Armistead y Silverman la situaban dentro de las adi-

${ }^{77}$ Bermejo Meléndez, Adivinanzas, 68, núm. 346.

${ }^{78}$ GÁrfer y Fernández, Acertijero popular, 231.

${ }^{79}$ Bermejo Meléndez, Adivinanzas, 55, núm. 260. Véase además la explicación que introduce a continuación la autora con respecto a esta adivinanza, vinculándola con el cuento de Blancanieves y los siete enanitos de Jacob L. Grimm.

${ }^{80}$ GÁRFER y FERnÁNDEZ, Acertijero popular, 214 y 222.

${ }^{81}$ LuRIA, A Study of the Monastir Dialect, 412.

${ }^{82}$ Galante, Appendice à l'Histoire des Juifs, 23. 
vinanzas judeoespañolas de Turquía: «Abaša riendo, / asuve yorando» ${ }^{83}$ y ellos mismos la encontraban también en la Colección Milwitzky de Estambul: «Riyendo abaxa, / yorando suve» ${ }^{84}$. En castellano: «Cuando baja, va cantando / cuando sube, va llorando» y «Baja riendo / y sube llorando» ${ }^{85}$.

Por último, destaca que entre los acertijos que se han conservado en judeoespañol haya algunos que se repiten formulados de manera bastante similar y que hacen referencia al caballo, a la oreja, el rábano, el sol, etc. y que no aparecen tampoco en la Ilustra Güerta de Historia.

\section{Las Posibles fuentes de las adivinanZas de ILUSTRA GÜERTA DE HISTORIA}

Hace ya décadas, Samuel G. Armistead y Joseph Silverman se plantearon si algunas de estas manifestaciones de la literatura oral y tradicional sefardí tenían un origen hispánico medieval y, por tanto, pertenecían al bagaje cultural de los sefardíes antes de su expulsión de las Coronas de Castilla y Aragón y reino de Navarra, o bien habría que tener en cuenta otros factores, como fue la influencia del contacto de las comunidades sefardíes con otras sociedades y culturas a lo largo de su diáspora ${ }^{86}$. Lo mismo podemos decir respecto a estos acertijos y adivinanzas que aparecieron en la Ilustra Güerta de Historia, ya que no podemos conocer cuáles han podido ser con exactitud sus posibles fuentes.

Sabemos que, en ocasiones, los directores y editores de esta prensa judeoespañola tomaban sus materiales de otras publicaciones periódicas ${ }^{87}$,

${ }^{83}$ Armistead y Silverman, «Adivinanzas judeo-españolas de Turquía», 89, núm. 8.

${ }^{84}$ Armistead y Silverman, «Nueve adivinanzas de Estambul», 43, núm. 5.

85 Ambas en Miaja y Cerrillo, Sobre 'zazaniles', 89 y 114.

${ }^{86}$ Como muestras de estos problemas pueden verse los dos trabajos de M. SÁnchEZ PÉrez: «Los refranes de la revista sefardí Yerushalayim (1909)», Paremia 19 (2010), 53-60; y «Entre escritura y oralidad: cuentos tradicionales en el periódico sefardí Yerushalayim (1909)», en DíAz-MAS y SÁNCHEZ PÉREz (eds.), Los sefardíes ante los retos del mundo contemporáneo, 193-202.

${ }^{87}$ Véanse, por ejemplo: BARQuín y DíAZ-MAS, «Relaciones entre la prensa española y la prensa sefardí a finales del siglo XIX», en MARTín AsUERO y GERSON SHARON (eds.), Ayer y hoy de la prensa en judeoespañol, 38-46; y P. DíAz-MAs (en prensa), «Periódicos que se 
pero también se hicieron numerosas traducciones. De hecho, de los acertijos que aparecieron en el número 9 del volumen I (núm. 33-44) de la Ilustra Güerta de Historia se señala explícitamente que son «treśladado de la lingua rumena». Nada se nos dice de todos los demás acertijos que aparecieron en esa publicación, pero sí sabemos, por tanto, que doce de ellos fueron traducciones del rumano.

Creemos que lo más acertado será retomar las palabras que encabezaban las adivinanzas que recogió David Elnecavé: «[ellas] constituían una de las más estimadas diversiones en las reuniones íntimas familiares o sociales» ${ }^{88}$. Si sabemos que, junto con otras manifestaciones de la literatura tradicional en judeoespañol, las adivinanzas eran muy del gusto de la sociedad sefardí, parece más que probable que, en esta ocasión, Šem Tob Semo tomara esos acertijos de todas las culturas que hubiese conocido -recordemos que se había formado en Sarajevo y tiempo después se había traslado con su familia a Austria-.

Parece, por tanto, que las fuentes de las adivinanzas publicadas en la Ilustra Güerta de Historia tienen procedencias diversas: desde luego, la propia tradición oral sefardí, que en parte conserva elementos de la tradición hispánica y en parte incorpora influencias de las culturas de los países de asentamiento de los sefardíes en su diáspora; pero también incluyeron traducciones de acertijos en otras lenguas, cosa que a veces se señala explícitamente -como en el caso de las adivinanzas traducidas del rumano que hemos mencionado- y otras veces no. En muchas ocasiones, lo que se vislumbra al analizar todas estas manifestaciones de la cultura tradicional -cuentos, refranes, acertijos, etc.- es que los editores de esta prensa sefardí pretendían ofrecer a su público unos contenidos que eran, al mismo tiempo, entretenidos e instructivos, y gracias a su iniciativa ha llegado a nuestro conocimiento una parcela de la literatura oral que de otra forma hubiera caído fácilmente en el olvido.

informan a través de periódicos: las fuentes de información de El Lucero de la Pasensia», en R. SÁnchez y M.-C. Bornes Varol (eds.), La presse judéo-espagnole, support et vecteur de la modernité (Estambul: Libra).

${ }^{88}$ ELNECAVÉ, «Folklore de los sefardíes», 326. 


\section{GLOSARIO}

aỵolar 'volar'

abonemá (fr. abonnement) 'suscripción'

aborecer 'aborrecer'

aboreción 'aversión'

afalagar 'reconfortar, consolar'

algujáa 'aguja'

altigüeza 'altivez, arrogancia'

aníos 'anillos'

arabiar 'enfadar'

arecodrar 'recordar'

arobar 'robar'

artificiośo 'hecho con artificio, artesano'

asabentar 'hacerse sabio, aprenden'

asufrido 'con sufrimiento, con padecimiento, trabajosamente'

aver (hb. אויר) 'aire', 'atmósfera', 'viento'

binear (tc. binmek) 'montar a caballo, cabalgar'

buraco 'agujero'

cadifé (tc. kadife) 'terciopelo'

caras 'rostro, mejillas'

carta (cfr. fr. carte, it. carta) 'mapa'

cartófel (al. Kartoffel) 'patata'

chiźmeź (tc. çizme) 'bota'

civdades 'ciudades'

comandador 'el que ordena, el que da las órdenes'

con yo 'conmigo'

consentir 'notar, sentir, darse cuenta'

costía 'costilla'

cosur (tc. kusur) 'defecto'

covear 'perseguir'

crianza 'criatura, ser vivo'

criatura 'bebé, niño pequeño'

culebía (tc. kulübe) 'cabaña', probablemente aquí en el sentido de 'nido'

deśmolar 'afilar'

desrepośar 'alterar, inquietar',

devdores 'deudores' 
devista 'enseguida, inmediatamente'

doĝe 'doce'

dunque (it. dunque) 'pues, por consiguiente'

embeleco 'engaño'

enbelecar 'engañar'

enṿeźar 'enseñar'

endevina 'adivinanza'

entero 'entierro, enterramiento'

enverán 'verano'

eo 'ello'

formea 'forma'

gaínas 'gallinas'

hackino 'enfermo'

jugar 'jugar, tocar un instrumento'

laboro (it. lavoro) 'trabajo'

lišo 'liso'

luenga 'lengua'

llamador 'avisador'

manzana del ojo (al. Augapfel) 'globo ocular'

matar 'apagar'

melećina 'medicina'

menester 'necesidad'

meollo 'cerebro'

modre, para $\sim$ 'a causa de'

muermo ‘aburrido' (¿por tuerto?)

musafir (tc. müsafir) 'anfitrión, huésped'

oe 'oye'

onde 'donde, adonde'

péndola 'pluma para escribir'

pericolośa (it. pericolosa) 'peligrosa'

peśgada 'pesada'

prestośas 'apresuradas'

preta (pt. preta) 'negra'

probe 'pobre'

punchones 'púas, espinas, aguijones'

québer (hb. קבר) 'fosa, tumba' 
šematá (hb. שמתא) 'excomunión, anatema', en este caso, con el sentido de 'barullo, jaleo'

soḅa (tc. soba) 'estufa'

solde 'sueldo, un tipo de moneda'

solombra 'sombra'

statuta 'figura'

stopa 'estopa, tela gruesa'

topar 'encontrar'

tósego 'veneno'

Recibido: 07/12/2012

Aceptado: 28/05/2013 